\title{
Inundaciones en Centroamérica
}

Una vez más, Centroamérica vuelve a ser noticia en las planas de los medios informativos alrededor del mundo. Hace poco menos de un año, las necesidades de los países más vulnerables de la región se convirtieron en el centro de los debates para la comunidad intemacional, que vio con preocupación las secuelas dejadas por el inclemente paso de la tormenta tropical "Mitch" en la zona. Por primera vez en muchos años, se hizo patente la urgencia de elaborar un plan integral de desarrollo que no sólo se dedicara a solventar necesidades de tipo económico y/o material, sino que también posibilitara mejoras cualitativas en las oportunidades de superación de los sectores más necesitados. Se contaba, entonces, con el apoyo de las potencias mundiales (atadas a nuestros países por las exorbitantes deudas que alimentaban), el de la prensa internacional y con la presión de diferentes grupos sociales que, desde el interior mismo de las naciones más afectadas, dirigían sus esfuerzos hacia la definición de ese nuevo progreso esperado para la región.

Ahora, a escasos once meses de ocurrida aquella tragedia, nuevamente alimentamos la maquinaria de la información global. No obstante, en esta ocasión las diferencias entre una situación y la otra han sido decisivas para marcar el rumbo de las acciones pertinentes para la reparación del daño. En primer lugar, los orígenes de la tragedia no son tan espectaculares como hace un año; por el contrario, son sólo los efectos de una temporada de lluvias atrasada por el efecto del El Niño. Por lo tanto, no debe extrañar que el apoyo internacional no se haya decantado con la misma intensidad que el año pasado. La respuesta de los gobiemos regionales ha sido, en cierta medida, más organizada y se ha alejado bastante de la estrategia publicitaria que se gestó alrededor del "Mitch", en un intento por ensanchar las arcas esta- tales con la ayuda intemacional. Hasta se podría decir que en el caso actual se contaba con las reservas suficientes para hacer frente - a corto plazo o a mediano, a lo mucho- a la naturaleza de la crisis que esos "días de lluvia" provocaron.

Sin embargo, al examinar con atención los efectos que esta crisis dejó en los países de la región no tardan en sobresalir los mismos males que por tanto tiempo flotaron en el ambiente de devastación y desamparo dejado por el "Mitch". Pareciera que las lluvias que trajo el huracán nunca dejaron de caer sobre estas tierras y que la ruina que sustituyó paisajes enteros y cultivos de vital importancia para las economías regionales, la ciega fuerza con la que fueron amebatadas miles de vidas junto con las esperanzas de millones de habitantes de la región, no desapareció con la partida de ese prolongado invierno de 1998. En este momento, los datos combinados de los cinco países de la región arrojan cifras preocupantes: más de 70 personas han muerto, se han producido 43023 evacuaciones a causa de las numerosas inundaciones y aproximadamente 100000 personas han perdido sus hogares temporal o definitivamente. Se ha perdido el equivalente a 40 millones de dólares en cosechas, se teme un rebrote acelerado de enfermedades como el cólera, el dengue hemorrágico y clásico, la malaria y otras enfermedades respiratorias o gastrointestinales y la posibilidad de que sobre la zona atlántica de Nicaragua y el norte de Honduras se produzcan más precipitaciones a causa del arribo de una nueva onda tropical'.

En las siguiente líneas se intentará esbozar un panorama general de los matices que esta nueva crisis ha adoptado en los países más afectados de la región -El Salvador, Honduras, Nicaragua, Costa Rica y Guatemala-, no tanto para hacer un mapa de

1. Algunos de estos datos han sido recogidos por el Programa de Alimentos para el Mundo, dependiente de la ONU, y fueron publicados el 9 de octubre pasado. 
la tragedia, sino para subrayar con mayor énfasis la importancia de discutir a fondo las rutas que debería tomar, en el futuro, una estrategia de despegue económico y de recuperación medioambiental para la región.

\section{El Salvador: ausencia de una política nacional de desastres}

Durante la década de 1990, la problemática de las inundaciones en las zonas costeras del país se ha agudizado a tal grado que prácticamente éstas se repiten todos los años y para 1998 — a causa de la depresión tropical "Mitch" - fueron catalogadas como las de mayor envergadura del siglo XX. 1999 no ha sido la excepción y prácticamente desde mediados de septiembre, con el inicio de la temporada más lluviosa del inviemo, los desastres provocados por inundaciones se hicieron presentes nuevamente.

Desde el día 9 de septiembre y hasta los primeros días de octubre acumularon pérdidas agropecuarias, daños en los hogares y degradación de los ecosistemas, especialmente en la parte baja de los ríos Lempa y Grande de San Miguel, en la desembocadura del río Paz, en algunas secciones del nóo Goascorán y en al menos siete comunidades de San Salvador ubicadas en riberas de rios y quebradas. Según las cifras definitivas dadas a conocer por el COEN y el Ministerio de Agricultura y Ganadería (MAG) se habían contabilizado, hasta el 5 de octubre, tres muertos y 2604 refugiados a causa de las inundaciones, además de pérdidas agropecuarias por un monto cercano a los 25 millones de colones, siendo los cultivos de granos básicos los más afectados, pues en este rubro se concentraron un 80 por ciento de las pérdidas, es decir, cerca de 20 millones de colones. Luego de esa fecha, las autoridades aseguraron que lo peor para nuestro país había pasado.

Se han sumado unas 50498 manzanas de área afectada en el país y, aunque de acuerdo al MAG, estos daños representan solamente un 2 por ciento de la producción agropecuaria total para los productores afectados, en realidad implican pérdidas que van desde el 70 al 100 por ciento, con el agravante de que en la mayoría de casos las familias afectadas se encuentran en situación de pobreza. Así, desastres que algunos catalogan como "pequeños", representan grandes pérdidas para los afectados de las zonas más vulnerables.

Esta dinámica induce a pensar sobre las posibles formas en que podría enfrentarse el problema del creciente impacto de las inundaciones, dando por descontado que los desastres no son solamente "naturales", sino más bien el producto de factores de amenaza y vulnerabilidad que, en la mayoría de casos, son construidos socialmente. Lamentablemente, hasta ahora los problemas generados por los desastres no están siendo abordados desde una óptica de mediano y largo plazo, dirigida a la prevención y mitigación, sino más bien a la organización y preparativos para hacer frente a desastres ya consumados.

De hecho, no es difícil demostrar que las acciones del ente encargado de la protección contra desastres, el Comité de Emergencia Nacional (COEN), se ubican principalmente durante e inmediatamente después del desastre, sea de la naturaleza que sea. Esto se comprueba al revisar las memorias de labores del Ministerio del Interior en la parte correspondiente al COEN y, más recientemente, con las acciones realizadas durante las inundaciones de 1999. Esta forma de enfocar el problema ha demostrado claramente su incapacidad para evitar o reducir el impacto de futuros desastres.

El presidente Francisco Flores sostuvo que en cuanto terminara el inviemo, se iniciaría "la reconstrucción de las bordas, el dragado de los lechos de los ríos y la reparación de caminos y carreteras dañadas". En esta línea, el ofrecimiento más polémico de Flores ha sido el de "despoblar" la zona del bajo Lempa, lo cual implicaría el traslado de las familias hacia zonas de menor riesgo, ante lo cual varios representantes de gremiales comunales de la zona sostienen que la solución tendría que orientarse más bien al desarrollo de obras de infraestructura.

Es un hecho que la problemática de los desastres trasciende con mucho las capacidades del COEN o las meras acciones de enfrentar la emergencia practicadas por el actual gobiemo. Se requiere la integración de un sistema nacional de prevención de desastres que valore el problema en su verdadera dimensión e incorpore la prevención y mitigación en la planificación del desarrollo. Lamentablemente, hasta ahora el gobierno continúa cerrándose a la realidad y pretendiendo que las acciones que desarrolla son las más razonables, cuando la cruda realidad demuestra fácilmente que existen muchas actividades orientadas al "desarmollo" que en realidad lo que han generado son condiciones socioambientales que favorecen la vulnerabilidad frente a los desastres, como por ejemplo la construcción apresurada y mal planificada de represas hidroeléctricas y el poco 


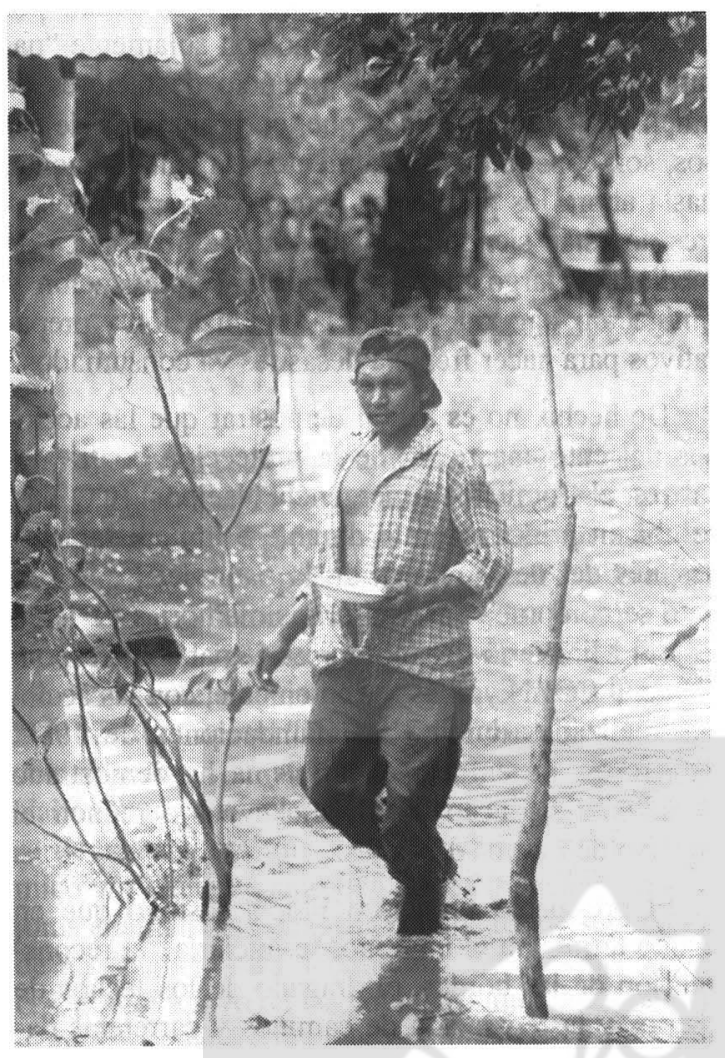

controlado proceso de reasentamientos que se dio cuando finalizó el conflicto armado.

A nadie escapa que las descargas de las represas hidroeléctricas - y especialmente de la 15 de septiembre- están directamente relacionadas con las inundaciones en la parte baja del río Lempa, la cual se ha convertido en la zona más afectada por las inundaciones. Paradójicamente, las represas fueron construidas no sólo con el objetivo de generar electricidad, sino también el de prevenir estas inundaciones, de las cuales se tiene noticia desde la década de 1930. Evidentemente, aquí existe un fallo de planificación de largo plazo que requiere de acciones correctivas urgentes de parte del gobiemo. Adicionalmente, muchos de los asentamientos ubicados en ambas márgenes de la parte baja del río Lempa fueron deliberadamente creados allí, a partir de un pacto incluido en el acuerdo de paz entre el gobierno y el FMLN. Ello implicó el poblamiento de una planicie de inundación, que se encontraba aun con mayor riesgo debido a la deforestación masiva realizada en la década de 1950 para la intensificación del cultivo del algodón en El Salvador y, por supuesto, también debido a las descargas de las represas.

\section{La suerte de Guatemala y Costa Rica}

Tanto Guatemala como Costa Rica han sido los menos golpeados por las precipitaciones que se registraron en la región. Sin embargo, la identificación de zonas afectadas y la evacuación de las víctimas se dificultó más en Guatemala debido a que la mayoría de las zonas de riesgo se ubicaban en el interior de este país, en asentamientos indígenas característicamente aislados de los centros departamentales. Se estima que más 17 mil personas fueron evacuadas de estos lugares, incluyendo aquellas de las zonas marginales en la capital guatemalteca. El informe oficial presentado por la Coordinadora Nacional para la Reducción de Desastres (CONRED) determinó que el saldo de muertos ascendía a 11, más de 1500 personas perdieron sus hogares, 1822 personas se encontraban aún en situación de riesgo y otras 14 estaban heridas o enfermas. Estos datos fueron revelados hasta el 9 de octubre, cuando las lluvias todavía representaban una amenaza para la mayoría de zonas de alto riesgo. Sin embargo, la celeridad en la publicación de información actualizada de la crisis no ha sido una constante en los gobiemos regionales, al menos no de la forma como se produjo durante el paso del "Mitch".

Quienes sí se dedicaron ágilmente a evaluar las pérdidas han sido los representantes de la gran empresa guatemalteca y, en general, así ha sido en los demás países de la región. De hecho, los primeros datos sobre pérdidas en el sector agrícola que se difundieron a escala internacional provienen de balances hechos por terratenientes y asociaciones de productores del ramo. Según sus estimaciones, cerca de 1,9 millones de dólares se han perdido a causa del deslave de cultivos de variada naturaleza. Luego, el CONRED calculó que las pérdidas sólo alcanzaban 1 millón 583 mil dólares en cultivos de maíz, ajonjolí, plátano, soya y arroz (5 806 manzanas de terreno afectadas). Además, se informó que cerca de 3000 viviendas fueron afectadas por el temporal y 8 puentes quedaron dañados 0 , simplemente, intransitables.

Por su parte, las autoridades de Costa Rica empezaron con pie derecho los operativos de desalojo y reubicación de las familias en peligro por las lluvias. En total, 60 albergues en todo el país recibieron a unas 5600 personas, en tanto que el número de muertos llegó a 10. Pero al día siguiente, sólo en el departamento de Guanacaste se estimó que cerca de 4000 personas permanecían en centros de resguardo. Con gran preocupación, las autoridades del Mi- 
nisterio de Obras Públicas y Transporte determinaron el monto definitivo de los daños en la infraestructura: 6 millones 867 mil dólares, incluyendo red vial y viviendas ${ }^{2}$. Hasta la fecha, el gobiemo de Miguel Angel Rodríguez ha ofrecido unos $13 \mathrm{mil} \mathrm{mi-}$ llones de dólares para empezar la reconstrucción de los tramos inhabilitados por las lluvias. Por otra parte, se dijo que unas 2300 hectáreas de cultivos de arroz, caña de azúcar y maíz se habían perdido por las Iluvias, siendo las provincias de Guanacaste y Puntarenas las más afectadas.

\section{Nicaragua y Honduras: enfrentados a una nueva tragedia}

Por desgracia, estos dos países han sido los más afectados con la agudización de las lluvias de septiembre y octubre de 1999. Sin haber logrado materializar un plan de acción inmediata para prevenir eventuales situaciones de crisis en las zonas de alto riesgo, tanto nicaragüenses como hondureños han tenido que sufrir nuevamente la pérdida de propiedades, negocios, tierras cultivables y, en el peor de los casos, hasta de seres queridos. Los habitantes de aquellas regiones que el año pasado quedaron a merced de la naturaleza, hoy se mantienen en vilo por el temor de que la historia se repita. Al menos hasta el 5 de octubre, en Nicaragua se contaban 13 muertos a causa de deslaves, inundaciones u otros accidentes provocados por las lluvias. Asimismo, se hablaba de 7105 personas movilizadas por las operaciones de evacuación que, a diferencia de los dos países anteriores, no se habían detenido para entonces.

Las autoridades gubemamentales han demostrado poseer una logística muy pobre a la hora de enfrentar este tipo de desastres, puesto que a la fecha no se ha podido establecer ningún monto más o menos fiel de pérdidas en sectores estratégicos como el agropecuario; esta situación mantiene sumergido a este país en una incertidumbre casi tan peligrosa como las condiciones climatológicas que se gestaron durante las semanas de lluvia. Se ha adelantado un balance preliminar del Ministerio de Transporte e Infraestructura que establece daños hasta por $2 \mathrm{mi}$ llones 95 mil dólares. Frente a esto, el presidente Amoldo Alemán ha puesto a disposición de esta cartera 7 millones de dólares para iniciar los trabajos de reparación. Con respecto a las cosechas, el go- biemo no ha dado a conocer ninguna cifra oficial y únicamente se manejan cálculos realizados por la Unión Nacional de Agricultores y Ganaderos (UNAG), que revelaban que cerca de 38850 manzanas de terreno plantado se habian perdido completamente; esto representa un 34 por ciento de la cosecha total para el presente año. En ambos casos, tal y como ocurrió el año pasado, los departamentos más golpeados por el temporal han sido León, Rivas, Chinandega, Masaya, Jinotega, Matagalpa y Boaco.

Mientras tanto, en Honduras el número de muertes sobrepasó cualquier expectativa previa: 28 personas han perecido. Unas 15000 personas han sido evacuadas y varias comunidades volvieron rápidamente a quedar incomunicadas al verse rodeadas por caminos intransitables, ríos desbordados y puentes destruidos por los fuertes caudales. 28 vías de transporte están parcialmente dañadas y 2 son intransitables; 21 puentes están en mal estado o totalmente destruidos; 36547 manzanas de plantaciones de palma africana, caña de azúcar, maíz, anoz, sorgo, banano, plátano y hortalizas se han perdido, lo cual supone una importante disminución no sólo en la producción destinada al comercio en el exterior, sino también en aquella orientada a suplir las necesidades básicas de las familias hondureñas.

Frente a la evolución que progresivamente fue mostrando la situación nacional, el gobierno de Honduras ha sido el que ha dado la respuesta más organizada y ágil de la región. El presidente Carlos Flores Facussé no tardó en reorientar los remanentes de la ayuda recogida el año pasado para impulsar labores de reconstrucción dirigidas por los gobiemos locales. A parte de lo que cada rama del gobierno deberá invertir para rehabilitar las áreas que estén a su cargo, las municipalidades podrán disponer de unos 1435 millones de dólares para iniciar proyectos de reconstrucción urgentes. Los propietarios de pequeños negocios establecidos en los mercados afectados por las lluvias contarán con un fondo de 287 millones de dólares para refinanciamiento. Como medida a corto plazo, los presupuestos de los cuerpos de seguridad y del Comité Permanente de Contingencias (COPECO) han sido reforzados para que no detengan sus programas de emergencia en las zonas que más lo necesitan. Por su parte, la USAID ofreció un financiamiento de

2. Estos datos dan cuenta de 128 casas destruidas, 170 dañadas, $300 \mathrm{~km}$ de carreteras en mal estado y 17 puentes afectados por las lluvias. 
68 millones 93 mil dólares para paliar los daños sufridos en los cultivos de banano, sandía y en la crianza de camarones de la costa atlántica.

\section{La XX cumbre para prevención de desastres en Centroamérica y El Caribe}

En las postrimerías de la crisis, el papel de los gobiemos en la búsqueda de una solución, al menos a corto plazo, no estaba del todo claro. Casi todus los países del Istmo habían levantado la alerta roja o la emergencia nacional a principios de la tercera semana de octubre, pese a que la amenaza de más huracanes estaba latente, en especial en las costas atlánticas de Costa Rica y Nicaragua. La cautela y la reserva predominaron en el manejo de la ayuda internacional que, aunque poca, llegó a nuestras tierras para reducir los efectos de las lluvias. Los medios informativos internacionales, como se mencionaba al principio, se preocuparon más por cubrir el desastre que se vive en México - la novedad del momento- que por recalcar la necesidad de no abandonar la tarea de reconstrucción y recomposición de las economías de la región. Así, la iniciativa oficial enfiló sus recursos a la realización de una reunión cumbre cuyo tema central fue la elaboración de un plan estratégico de reducción de la vulnerabilidad frente a los desastres ${ }^{3}$.

Pero a lo largo de los textos que emanaron del evento no queda del tódo claro si en verdad existe una voluntad dirigida por esos ejes que motivaron la reflexión de los gobiernos nacionales: impulso de un proceso integral de transformación y desarrollo sostenible para la región, elaboración de políticas y medidas de prevención de daños y poner en práctica acciones de preparación y gestión de las emergencias, cuando estas se presenten. En reuniones preparatorias se elaboró un Marco Estratégico que contempla una serie de medidas orientadas a la reducción de desastres, la conservación de recursos hidrológicos y la prevención de incendios forestales. Pero los compromisos adquiridos en materia de fortalecimiento económico, reconstrucción de las zo- nas afectadas por las lluvias y por el huracán "Mitch" y coordinación de actividades regionales para la reducción de daños por desastres no se equilibran con todos los que se refieren a defensa del espacio marítimo, supervisión de actividades financieras, creación de mecanismos de solución de controversias interregionales, control de emisión de gases y encomiar el próximo traspaso del Canal de $\mathrm{Pa}$ namá a la administración nacional.

Esta cumbre, por sí misma, no debería representar ningún motivo de esperanza para las personas que más han sufrido con la crisis, anunciada, de un invierno copioso. A través de ella se cumplieron todo tipo de requerimientos de carácter "ordinario" que necesitaban el aval de los ejecutivos de los países de la región, y nada más. La prensa intemacional - acaso desconocedora de la necesidad de retomar la discusión sobre la recomposición centroamericana- alabó la urgencia con la que, dentro de una cumbre casualmente programada en una coyuntura de evidente zozobra, los presidentes dieron un paso al frente y aprobaron el Marco citado. Pero la tan urgida visión a largo plazo que se esperaba fuera cristalizada dentro de los documentos a aprobar nunca llegó a la mesa de trabajo. Lo que verdaderamente urgía era ratificar el Marco Estratégico, puesto que este se presentaba como el requisito inamovible que los países de grupo consultivo en Estocolmo plantearon para proceder con la ayuda económica prometida para la reconstrucción regional.

Si los puntos contenidos en el primer capítulo de dicha guía de acción legan a ser aplicados con efectividad por los organismos encargados para ello, probablemente podamos presenciar un renacer de las políticas para enfrentar desastres ${ }^{4}$. A lo sumo, podríamos presenciar una que otra discusión en los órganos legislativos de los países de la región acerca de la necesidad de coordinar el rescate de zonas de alto riesgo, la conservación de reservas naturales y la reducción de la vulnerabilidad arraigada en la estructura misma de las sociedades centroamericanas. Todo ello no obsta para pensar que las gestiones gu-

3. La XX Reunión Ordinaria de Presidentes de Centroamérica y El Caribe se llevó a cabo el $\mathbf{1 9}$ de octubre, en la ciudad de Guatemala. En ella participaron los presidentes de El Salvador, Costa Rica y Guatemala, junto a representantes de los gobiemos de Honduras, Nicaragua, Panamá, República Dominicana y Belice.

4. El Centro de Prevención de Desastres Naturales para América Central (CEPREDENAC), la Comisión de Seguridad Centroamericana y los diferentes consejos de ministros de la región han sido designados para poner en práctica y verificar el cumplimiento de los compromisos adquiridos en materia de desastres en la cumbre. Para ello, el próximo año se inaugurará el Quinquenio Centroamericano para la Reducción de las Vulnerabilidades y el Impacto de los Desastres, en cuyo transcurso se deberían implementar todos esos acuerdos. 
bernamentales que vemos avanzar o recién aparecer desde Guatemala hasta Panamá no pasarán de ser meros pregonadores de un desarrollo sostenible que está lejos de asomarse para la población más desvalida del Istmo.

\section{Consideraciones finales}

Las lluvias en la región centroamericana siguen siendo una amenaza latente $e$ incontrolable. $Y$ aunque durante esta temporada de lluvias no se espera que la crisis se asemeje a la dejada por el huracán "Mitch" hace un año, es necesario asumir el llamado de atención que sus efectos implicaron para los países del Istmo y para los países que pretenden llevar de la mano su desarrollo futuro. No se trata únicamente de "darse cuenta" de la fragilidad de las economías, de la ausencia de recursos y de la incapacidad de manejar con diligencia situaciones de esta índole. Eso quedó más que resaltado el año pasado. Ahora, se trata de poner los puntos sobre las "íes" en el abandonado proceso de recomposición de las naciones icentroamericanas.

Esto no significa otra cosa más que entrar de lleno al análisis de las condiciones previas para impulsar un verdadero proyecto que no potencie únicamente el progreso económico, sino también el perfeccionamiento de los débiles sistemas productivos con los que la región pretende enfrentarse al nuevo siglo. Y este proceso debe pasar, por lo menos, por una redefinición concertada del papel que los sectores sociales estratégicos (sociedad civil, empresa privada, comunidad internacional, gobierno, franjas de trabajadores, etc.) deberán jugar en el mantenimiento de un nuevo modelo; por el establecimiento de mejores controles sobre el destino y la utilización de la ayuda internacional; por la potenciación del desarollo local con participación social; y, como varios analistas han venido insistiendo, por la necesaria adopción de compromisos que no se funden en razones humanitarias, inspiradas por emergencias (que después de todo son pasajeras), sino que se lacen sobre la base de proyectos a largo plazo y con una profunda vocación social.

En el caso de nuestro país, de lo que se trata es de diseñar una nueva estrategia para enfrentar la problemática de los desastres, cuya meta sea el estudio profundo de sus causas reales para, a partir de ello, articular un plan para erradicar las condiciones que favorecen su ocurrencia. En este sentido, todos los fenómenos - tanto naturales como sociales- que acompañan a estas crisis deben ser abordados desde una óptica más estructural, que rompa con la contingencialidad que caracteriza el trabajo de los organismos de emergencia creados en cada país del área centroamericana.

Así, las inundaciones no son el simple resultado de las precipitaciones pluviales, sino que son el efecto a largo plazo de la reducción de la capacidad que tiene la tierra para absorber el agua sin provocar mayores daños. Actividades como la deforestación, la desecación de pantanos y la construcción de obras de infraestructura sin ninguna previsión contra desastres se convierten en verdaderas amenazas de tipo socio-natural para la población. A esto hay que sumar la evidente debilidad del Estado para articular planes efectivos para mitigar los desastres, la relativa desorganización de las comunidades en las zonas de riesgo, las características de las viviendas y los asentamientos que se han desarrollado, los tipos y las técnicas de cultivo que se practican actualmente, los bajos niveles educativos y los bajos ingresos; todos ellos constituyen factores de vulnerabilidad para la población nacional.

Lo anterior sugiere, en consecuencia, que los desastres no deben enfrentarse desde la óptica que ha venido haciéndose tradicionalmente; es decir, ejecutando acciones para atender emergencias, sino que más bien requiere la intervención de diversos actores: no solamente aquellos que ejecutan tareas de rescate y búsqueda, sino también de los que planifican el uso del territorio, el uso de los recursos naturales y la construcción de obras de infraestructura, en coordinación con la población en general. Así pues, las acciones para enfrentar el problema de los desastres que debe implementar el Estado pasan necesariamente por una nueva visión de planificación del desarrollo, pero en el corto plazo requiere que se redefina la forma en que se enfrentan los desastres, se trascienda el simple manejo de los mismos y se adopten las necesarias medidas de prevención y mitigación para eliminar las condiciones que los favorecen; de lo contrario cada vez estaremos más ocupados atendiendo emergencias y enfrentando pérdidas innecesarias.

\section{Centro de Información, Documentación y Apoyo a la Investigación (CIDAI) Universidad Centroamericana "José Simeón Cañas"}




\section{América Central \\ Cifras de la temporada de lluvias septiembre-octubre/99}

\begin{tabular}{|c|c|c|c|c|c|}
\hline & El Salvador & Guatemala & Honduras & Nicaragua $^{3}$ & Costa Rica 6 \\
\hline Muertos & 3 muertos $(5 / 10)$ & $\begin{array}{l}10 \text { muertos }(9 / 10)^{7}, 1 \\
\text { desaparecido y } 14 \text { beridos o } \\
\text { enfermos }(9 / 10) \text {. }\end{array}$ & $28(7 / 10)$ & $13(5 / 10)$ & $10(6 / 10)$ \\
\hline Evacuados & 2604 personas $(5 / 10)$ & Más de $17000(12 / 10)$. & Aprox. $15000(9 / 10)^{8}$. & $7105(5 / 10)$ & $\begin{array}{l}5600 \text { en } 60 \text { albergues, aunque } \\
\text { para el } 6 \text { de octubre, sólo en } \\
\text { Guanacaste se calculó que unas } \\
3918 \text { personas ocupaban ya } 51 \\
\text { albergues }(5 / 10) \text {. }\end{array}$ \\
\hline Damnificados & & $1560(9 / 10)$ & $8000(9 / 10)$ & s.d. & s.d. \\
\hline $\begin{array}{l}\text { Daños a } \\
\text { infraestructura }\end{array}$ & $\begin{array}{l}1151 \mathrm{~km} \text { de red vial dañada, que } \\
\text { equivalen a } 1 \text { millón } 478 \mathrm{mil} \\
\text { dólares }(5 / 10) \text {. }\end{array}$ & $\begin{array}{l}\text { Aprox. } 3000 \text { viviendas infec- } \\
\text { tadas, } 8 \text { puntos dañados o in- } \\
\text { transitables }(21 / 10)\end{array}$ & $\begin{array}{l}21 \text { puentes, } 10 \text { escuelas, } 28 \\
\text { carreteras y } 96 \text { casas }(9 / 10)\end{array}$ & $\begin{array}{l}14 \text { viviendas destruidas y } 112 \\
\text { dañadas(?) } 2 \text { millones } 93 \text { mil } \\
\text { dólares en daños a carreteras, } \\
7 \text { puentes y demás infraestructu- } \\
\text { ra }(5 / 10)\end{array}$ & $\begin{array}{l}128 \text { viviendas destruidas y } \\
\text { otras } 170 \text { dañadas. } 300 \mathrm{~km} \text { de } \\
\text { infraestructura vial quedó inha- } \\
\text { bilitado, incluyendo } 17 \text { puentes } \\
6 \text { millones } 867 \text { mil dólares } \\
\text { incluyendo la red vial y } \\
\text { viviendas }(6 / 10) \text {. }\end{array}$ \\
\hline $\begin{array}{l}\text { Pérdidas en } \\
\text { cultivos }\end{array}$ & $\begin{array}{l}\text { Equivalentes a } 2 \text { millones } 844 \\
\text { mil dólares. Los granos básicos } \\
\text { fueron los más afectados, puesto } \\
\text { que este rubro se concentró el } \\
80 \% \text { de las pérdidas }\end{array}$ & $\begin{array}{l}1 \text { millón } 583 \text { mil dólares en } \\
\text { cultivos de maíz, ajonjolí, } \\
\text { platano,soya y amoz, equiva- } \\
\text { lentes a5 } 806 \text { manzanas. } \\
(21 / 10) \text {. }\end{array}$ & $\begin{array}{l}36547 \text { manzanas de banano, pla- } \\
\text { tano, caña, palma, granos básicos, } \\
\text { maíz, arroz, sorgo y hortalizas } \\
\text { equivalentes a } 10 \text { millones } 911 \\
\text { mil dólares ( } 7 / 10) \text {. }\end{array}$ & $\begin{array}{l}38850 \text { manzartas de terreno } \\
\text { cultivado, que representan } \\
34 \% \text { de la producción total } \\
\text { año (NAG. } 5 / 10 \text { ). }\end{array}$ & $\begin{array}{l}2234 \text { hectáreas de arroz de } \\
\text { azúcar y maíz }(6 / 10) \text {. }\end{array}$ \\
\hline
\end{tabular}

Fuentes: periódicos de Centroamérica, Centro de Coordinación para la Prevención de Desastres en América Central (CEPREDENAC), Guatemala Hoy (información por Internet) y Mesoamérica (boletín mensual). El dato entre paréntesis corresponde a la fecha en que la información fue publicada. Todos los datos de este cuadro corresponden a la última actualización dada a conocer por los respectivos organismos de emergencia de los países de la región.

s.d.: Sin datos.

5. Nicaragua ha sido el único país que no ha presentado, hasta la fecha, ningún consolidado definitivo de los daños provocados por las lluvias.

6. Hasta el 13 de octubre, la Comisión Nacional de Emergencias (CNE) calculó un total de 137 millones 357 mil dólares en daños a escala nacional, en todos los rubros aquí apuntados.

7. Cabe señalar que el último boletín Mesoamérica (del Institute for Central American Studies, ICAS) indica que sólo en Guatemala se registraron 16 muertes por ahogamiento. Empero, estos datos no son tompartidos por las autoridades gubernamentales del país.

8. Las tareas de rescate no fueron del todo exitosas en este país debido principalmente a la lenta reconstrucción que se inició tras el paso del "Mitch". De hecho, no se pudo evitar que unas 100000 personas quedaran aisladas durante lo peor de las lluvias y que los equipos de rescate penosamente pudieran hacerles llegar los suministros minimos para garantizar su supervivencia. 